\title{
A Preliminary Study on Teaching Foreign Undergraduates in the Course of Basis of Machinery Design
}

\author{
${ }^{*}$ Min Liu ${ }^{1}$ Chaoqun Don ${ }^{1} \quad$ Jie Meng ${ }^{1}$ Xianwu Han ${ }^{1}$ \\ ${ }^{1}$ School of Mechanical and Power Engineering,Chongqing University of Science and Technology, Chongqing, \\ China,401331 \\ *Corresponding author.e-mail: liuyijunpp2007@163.com
}

\begin{abstract}
With the continuous development of the international higher education in China, the education of foreign undergraduates has developed into an important part of higher education in China. However, considering the great differences between foreign students and Chinese students in the aspects of educational culture background and thinking mode, it is necessary to explore and establish a new teaching mode which is fully suitable for foreign students. With the studying experience aboard and teaching practice for overseas students, the author discusses and summaries the current problems in the teaching of foreign students, and puts forward some suggestions for improvement, which can provide a reference for the development of international students education in colleges and universities.
\end{abstract}

Keywords: full-English teaching, foreign student, teaching mode, textbook writing

\section{INTRODUCTION}

Chongqing University of Science and Technology is an application-oriented university with engineering characteristics. Since 2017, it has established a stable channel for foreign undergraduate students studying in China, covering engineering, science, management and other disciplines. The Increasing number of overseas students is not only an opportunity for the development of international education, but also a severe challenge for Chongqing University of Science and Technology.

The author went to Concordia University in Canada for a five-month study of the core courses of mechanical engineering under the funding of the "Three Special Action Plan" characteristic professional construction project of Chongqing undergraduate universities. After that, the author returned back to China to work as a course instructor of "Basis of Machinery Design" for foreign students. Combining with the studying experience aboard and teaching practice for overseas students, the author pursue a preliminary study on English teaching in the course of "basis of Machinery Design" for foreign students.

\section{PROBLEMS EXISTING IN THE COURSE TEACHING OF FOREIGN STUDENTS}

\subsection{Language problem}

Language problem has always been one of the key factors restricting international education[1]. Before coming to China, international students did not undergo systematic and comprehensive Chinese training, and their Chinese foundation was weak. After entering the university, they mainly used English for learning and communication. Teaching in full-English way will help foreign students to intuitively and accurately accept professional and technical knowledge, and greatly reduce the difficulty of studying in China. However, due to the weak base of international teaching, many teachers have undertaken the English teaching work without any systematic training. In particular, in terms of language, teachers have limited ability to use fluent English, and lack of knowledge of the teaching background of English courses. They often feel incapable of teaching foreign students.

\subsection{Severe shortage of textbooks}

The choice of English textbooks is another key factor affecting the teaching effect of international students' courses. Although many publishers have introduced original English textbooks in recent years, and many domestic scholars have compiled and published bilingual or all-English textbooks, there are few high-quality course textbooks suitable for foreign undergraduate students in China. At present, almost no English textbooks of "Basis of Machinery Design" are available in China suitable for teaching international students. The course content of "Basis of Machinery Design" includes two main parts: mechanical design and mechanical principle. Instead, two bilingual textbooks have been chosen as a replacement, they are "Machinery design" published by Wuhan University of Technology and "Theory of Machines and Mechanisms" published by Mechanical Industry Press. However, these two textbooks are not suitable for overseas students who have weak basic knowledge in science and engineering and huge cultural background differences compared with Chinese undergraduates, which often make them feel a loss whether in the aspects of the 
explanation of knowledge points or the analysis of case selection. Even the textbook of "Machine component Design" written by Robert C .Juvinall is widely used by foreign application-oriented universities, it is not suitable for foreign undergraduates in China neither, due to the high repetitiveness of the textbook content with the prerequisite courses "mechanics of materials", and the high cost.

\subsection{Single teaching method and teaching method}

Affected by the shortage of educational resources and test-oriented education in China, LBL (Lecture-based learning) teaching method, has occupied a dominant position in China's higher education. This "teacher-centered" teaching method is not conducive to mobilizing the enthusiasm of foreign students for learning and has the problems of developing their ability to think independently and analyze comprehensively[2]. Currently, most of the English teaching in the course of "basis of machinery design" for foreign students in China still uses the LBL teaching mode with "teacher speaking, student listening, zero interaction": teachers occupy an absolute dominant position in the classroom and teach theoretical knowledge step by step without any flexibility; Foreign students are basically aphasia in the classroom and receive knowledge passively. Such preaching unidirectional classroom teaching mode is extremely susceptible to make the foreign students feel boring, tired, and finally lost interest in learning. The classroom atmosphere is extremely dull. In foreign countries where the teaching environment is relatively open, classroom teaching is a communication between teachers and students around a theme: teachers' teaching only represents the words of themselves; students can question the teachers at any time, and freely express their different views on the same problem. The contradiction of the educational background between the China's traditional education and the foreigners' not only causes certain difficulties in foreign students' learning, but also sets up a barriers for the exchange and communication between teachers and students, let alone for cultivating their creativity and practical ability.

\section{RESPONSE MEASURES AND IMPROVEMENT METHODS FOR THE EXSITING PROBLEM}

\subsection{Overseas training and establishment of online courses}

As mentioned earlier, language issues have always been one of the key factors restricting the international teaching. A high-quality English teaching system will greatly reduce the difficulty of studying for foreign students and attract more overseas students to study in China. Combined with the studying experience aboard and teaching practice for overseas students, the following suggestions and improvement measures for the language problems are proposed.

\subsubsection{Strengthen teacher training and provide sufficient overseas training opportunities}

Overseas training is one of the effective ways to improve teachers' English teaching ability. Through overseas studies and international exchanges, we can comprehensively and deeply understand the concept of international education, absorb and introduce foreign high-quality teaching resources, and ensure the quality guarantee system for foreign students[1].

In recent years, our school attaches great importance to the international construction and training of teachers, and has established and provided a variety of overseas training opportunities for young and middle-aged teachers, which have greatly promoted the construction of bilingual and all-English courses. Most of them are scientific research-oriented projects, while few of them are reference to teaching research-oriented. In addition, the duration of most overseas training projects dedicated to curriculum teaching research is generally three months. Except for jet lag, familiarity with the study environment, and improvement of English listening and speak ability and preparations for returning to China, etc., only two months left for study actually, which is difficult for a trainee to study a course from beginning to end, let alone to ensure the training effect. It is highly recommended that the duration of overseas courses study specifically for curriculum learning should be extended to six months to improve and consolidate the effect of curriculum learning and teaching training.

\subsubsection{Fully carry out international cooperation and strengthen the construction of online courses}

In order to improve the flexibility of teaching, many universities in Canada offer online courses, and students can obtain corresponding credits by taking online courses. These online courses are generally conducted by the professor who has taught the course for many years. It also provides a large number of rich online learning resources and online Q \& A services. It is suggested that universities in China can cooperate with such overseas universities with the help of good international faculty and curriculum resources to quickly improve our university's English teaching level and curriculum construction level. It is also recommended that a full-English course teaching team should be established and all of the team members work together to strengthen the construction of English online courses, so as to provide continuous and strong support for the construction of full-English courses. 


\subsubsection{Pay attention to the "original" nature of English expression}

\subsection{Compile foreign undergraduates-oriented textbook}

As mentioned earlier, the full English textbook of "Basis of machinery design" is a key problem that needs to be solved in the teaching for foreign undergraduates. The problems of inappropriate content layout and high price of original foreign textbooks have limited their widespread use in China. To fully meet the actual teaching for overseas students in China, foreign undergraduates-oriented textbooks should be written by ourselves on the basis of referring to a large number of authoritative classic textbooks of this course from foreign universities. Based on the foreign curriculum learning experience and foreign student teaching practices, three issues need to be addressed in the process of textbook writing.

\subsubsection{Pay attention to the consistency of the textbook content layout and the talent cultivation plan}

It is well-known the talent cultivation plan is the basis for selecting and writing all-English course textbooks. It should be carried out in combination with the actual teaching and curriculum development needs. "Basis of Machinery Design" is an important professional basic course for engineering-related majors in colleges and universities, and provides the necessary theoretical foundation for students to study the subsequent professional courses. Therefore, properly handle the relationship between the prerequisite courses and follow-up professional courses in the cultivation plan oriented to overseas students, the reasonable integration of teaching content, and the construction of a curriculum knowledge system that is fully suitable for international students are the key to the writing of all-English textbooks.

\subsubsection{Pay attention to the practicality of textbooks}

Compared to the original English textbooks abroad, our textbooks tend to place more emphasis on theoretical and coherent knowledge, but lack of practicability of it. The writing of full-English textbook for "Basis of Machinery Design" oriented to foreign undergraduates should be based on the principle of project-driven to guide students to require the knowledge through discussion and conclusion in the process of problem analysis and solution. It will be divided into many corresponding engineering project units according to the chapters, and practical modules are established, focusing on the application of mechanical design and engineering problem improvement. At the same time, the writing of textbooks will also pay attention to the practical value of exercises and examples in the way of extracting various example from engineering application and production practice.
In order to integrate and adapt relatively "moderate" textbooks on the basis of absorbing the original English textbooks, teachers who write the textbook should be very familiar with international authoritative classic textbooks, and have a good English expression ability[3].

In addition, considering the high price of the original English textbook, library in the University should promptly expand the purchase of related textbooks and reference books to meet the borrowing need for international students and teachers.

\section{INNOVATING TEACHING METHODS TO STIMULATE THE ENTHUSIASM OF FOREIGN STUDENTS}

\subsection{Dual-track teaching mode with $L B L$ and $P B L$}

International students are very active in thinking, respond quickly, and ask questions immediately if they don't understand at any time, which is the biggest difference with Chinese students in classroom performance. Therefore, teachers should respect the class characteristics of international students and give full play it to guide them to think, ask questions and discuss, which can improve the students' class participation.

The PBL (problem-based learning) teaching mode is a problem-solving and self-learning teaching mode [4,5] , which can link learning with tasks and problems under the guidance of theoretical courses. In PBL mode, learners invest in problem solving, and use network resources to collect data and find solutions. Such teaching mode is more in line with the foreign students with the personality characteristics of active thinking, self-confidence, and independence. Based on the thinking and learning progress of foreign students[6], it is believed that the dual-track teaching mode that combines PBL with China's traditional LBL teaching mode applied in "Basis Machinery Design" will help resolve the contradiction between the traditional Chinese education model and the education background of foreign students. In the context of the basic national conditions of higher education in China, the dual-track teaching mode can stimulate students' learning initiative to the greatest extent and improve classroom teaching efficiency. In the process of practice, the dual-track teaching mode should adopt a combination of theoretical courses and PBL group learning together in order to guide student's grouping learning by theoretical knowledge, and promote the autonomous construction of theoretical knowledge by group learning[7] . 


\subsection{Reform the curriculum assessment method and improve the comprehensive application ability for foreign students}

It should be pay more attention to learning process evaluation and comprehensive assessment of the final result for foreign students. The classroom performance of foreign students shows a huge difference from Chinese students. So the curriculum assessment method should also be different. Although the international students' classroom performance is active affected by the influence of their educational background, their sense of organizational discipline is very weak. They often come to class late and left early, and even be absent. Therefore, in author's teaching practice, the strict attendance for international students was conducted, and the attendance status was an important assessment part of final result. As a result, the attendance rate has been increased and the learning atmosphere has been improved. In addition, various forms of process assessment methods such as classroom quizzes, group discussions, experimental operations, topic reports, homework assignments, and midterm exams have been introduced and the total evaluate rate of the process evaluation was increased up to $60 \%$ of the final result. Practice has proved that paying more attention to process evaluations and emphasizing the importance of ordinary learning can better mobilize international students' learning enthusiasm as well as effectively enhance their performance on analysis and application.

\section{CONCLUSIONS}

There is a huge difference between foreign students and Chinese students in various aspects such as thinking mode, educational and cultural background, etc. Therefore, the talent cultivation plan, education and teaching model and teaching methods for foreign students should be different from Chinese students. A higher requirement has been put forward to teacher in the class, not only the solid professional English and good communication skills, but also the innovation of teaching methods. There is still a long way to go for all-English teaching for foreign students, which requires continuous exploration and development from the educators.

\section{ACKNOWLEDGMENT}

This research was funded by the Chongqing Higher Education Teaching Reform Research Project under Grant No.163137 and by the Research Reform Project for Undergraduate Education and Teaching in Chongqing Institute of Science and Technology Grant No.201957.

\section{REFERENCES}

[1] Su Bo.Thinking about the teaching of international students in civil engineering [j] .Higher Architectural Education, 2015 (24): $26 \sim 27$

[2] Staff writers, problems with lecture-based learning, https://www.onlineuniversities.com (accessed Nov 2, 2011)

[3] Shan chen, Tianhong Pan. Research and Exploration of Full English Teaching of "Electrical and Electronic Engineering" Course [j] .Journal of Science Instruction, 2016 (24): 97 98

[4] Guo Fengjin, Lin Jianwei, Liu Ping.The exploration and practice of pbl interactive teaching mode in the teaching of foreign students [j] .Researches in Medical Education, 2009 (07): 773-775.

[5] Bound,D.(1985) Problem-based Learning in Education for the Professions. Sydney: Higher Education Research and Development Societiy of Australasia.

[6] Beasley, C(1997)Students are teachers: the benefits of peer tutoring. http://lsn.curtin.edu.au/tlf/tlf1997/beasley.html(accessed 2 February 2011)

[7] Kang Yinghua.The application of pbl interactive teaching mode in the teaching of foreign students [j] .Journal of Hulunbuir University, 2015 (23): 111 112 